\title{
Overt and Subclinical Hypothyroidism in the Elderly: When to Treat?
}

OPEN ACCESS

Edited by:

Andrzej Bartke,

Southern Illinois University School of

Medicine, United States

Reviewed by:

Bernadette Biondi,

University of Naples Federico II, Italy Anna Gruszka,

Salve Medica Medical Center, Poland

*Correspondence:

Valeria Calsolaro

valina82@gmail.com

Specialty section:

This article was submitted to Endocrinology of Aging,

a section of the journal

Frontiers in Endocrinology

Received: 23 November 2018 Accepted: 01 March 2019 Published: 22 March 2019

Citation:

Calsolaro V, Niccolai F, Pasqualetti G, Calabrese AM, Polini A, Okoye C, Magno S, Caraccio N and Monzani F

(2019) Overt and Subclinical Hypothyroidism in the Elderly: When to Treat? Front. Endocrinol. 10:177. doi: 10.3389/fendo.2019.00177
Valeria Calsolaro ${ }^{1,2 *}$, Filippo Niccolai ${ }^{1}$, Giuseppe Pasqualetti ${ }^{1}$, Alessia Maria Calabrese ${ }^{1}$, Antonio Polini ${ }^{1}$, Chukwuma Okoye ${ }^{1}$, Silvia Magno ${ }^{3}$, Nadia Caraccio ${ }^{1}$ and Fabio Monzani ${ }^{1}$

${ }^{1}$ Geriatrics Unit, Department of Clinical and Experimental Medicine, University of Pisa, Pisa, Italy, ${ }^{2}$ Neurology Imaging Unit, Imperial College, London, United Kingdom, ${ }^{3}$ Obesity Center at the Endocrinology Unit, Department of Clinical and Experimental Medicine, University of Pisa, Pisa, Italy

Hypothyroidism is characterized by increased thyrotropin (TSH) levels and reduced free thyroid hormone fractions while, subclinical hypothyroidism $(\mathrm{sHT})$ by elevated serum TSH in the face of normal thyroid hormones. The high frequency of hypothyroidism among the general population in Western Countries made levothyroxine (LT4) one of the 10 most prescribed drugs. However, circulating TSH has been demonstrated to increase with aging, regardless the existence of an actual thyroid disease. Thus, when confronting an increase in circulating TSH levels in the elderly, especially in the oldest old, it is important to carry an appropriate diagnostic path, comprehensive of clinical picture as well as laboratory and imaging techniques. In the current review, we summarize the recommendations for a correct diagnostic workup and therapeutic approach to older people with elevated TSH value, with special attention to the presence of frailty, comorbidities, and poly-therapy. The treatment of choice for hypothyroid patients is hormone replacement with $\mathrm{LT}_{4}$ but, it is important to consider multiple factors before commencing the therapy, from the age dependent TSH increase to the presence of an actual thyroid disease and comorbidities. When treatment is necessary, a tailored therapy should be chosen, considering poly-pharmacy and frailty. A careful follow-up and treatment re-assessment should be always considered to avoid the risk of over-treatment. It is important to stress the need of educating the patient for a correct administration of $\mathrm{LT}_{4}$, particularly when poly-therapy is in place, and the importance of a tailored therapeutic approach and follow-up, to avoid overtreatment.

Keywords: hypothyroidism, elderly, treatment, L-thyroxin, frailty

\section{MODIFICATION OF THE HYPOTHALAMUS-PITUITARY-THYROID AXIS IN THE OLDER PEOPLE}

In order to understand the modifications of thyroid axis, from hypothalamus to peripheral tissues, commonly observed during aging, it is noteworthy to briefly review the feed-back mechanisms that rules hormone secretion in young adults. Thyroid hormones are under the controls of TSH levels making the latter a sensitive marker of thyroid function. In this regard, circulating TSH levels in healthy subjects vary according to the circadian rhythm and respond with logarithmically variations to minor changes in serum $\mathrm{FT}_{4}$ and $\mathrm{FT}_{3}$ values (1). Thus, the occurrence of abnormal serum TSH in young adults may imply that serum $\mathrm{FT}_{4}$ and $\mathrm{FT}_{3}$ are not normal for that person 
(2). Accordingly, increased serum TSH values indicate a reduced thyroid function while lower TSH levels may underline a hyperfunction of the thyroid gland (3). Apart from specific thyroid diseases that may involve older people, the aging process per se plays a peculiar role on thyroid axis, from hypothalamus to peripheral thyroid hormone metabolism and action (46). The aging process leads to reduced iodine absorption and organification with an altered thyroid response to TSH. Moreover, changing in the TSH bioactivity, in the thyrocyte sensitivity to TSH, in thyroid hormone metabolism as well as in the receptors and co-factors modulating the response to $\mathrm{T}_{3}$ input has been described (7). Overall, these processes result in reduced thyroid hormone production (8-10). Interestingly, individuals older than 80-85 years presented a nocturnal surge of TSH partially or completely lost with attenuated inhibitory effect of corticosteroids thus, indicating an age depended hypothalamus impairment $(2,11,12)$.

A more complex relationship between TSH levels and the aging process has been described in several observation studies even while excluding patients with thyroid disease or autoimmunity. In fact, some experiences (generally casecontrol) showed a trend toward lower TSH circulating levels in individuals older than $75-80$ years and centenarians $(4,13)$, while more recent cohort studies demonstrated an opposite TSH level behavior during age with a shift toward higher values in older people. In particular, in subjects above 80 years of age, the upper limit of the $95 \%$ interval of confidence is around $6.0 \mathrm{mIU} / \mathrm{L}$, reaching $8.0 \mathrm{mIU} / \mathrm{L}$ in over-90 s (14-16). Some authors interpreted the reduced TSH levels in centenarians as a central reset of thyroid function in order to prevent an excessive catabolism favoring "physiological aging" $(4,17)$. It is noteworthy to differentiate this possible physiologic condition from that observed in acute patients and/or in starvation where TSH and $\mathrm{T}_{3}$ levels are reduced while reverse- $\mathrm{T}_{3}\left(\mathrm{rT}_{3}\right)$ is increased and a poor prognosis quoad vitam and quoad valetudinem has been described $(6,18)$. In general, we could hypothesize that the aging process acts for an individual as it does a hypothyroid status resulting in a reduction of the basal metabolism (19). However, to date, on the basis of previous experiences, it is impossible to state if the described reset of hypothalamus-pituitary-thyroid cross-talk in the elderly (due to either reduced TSH secretion or thyroid hormones production) is an effect of the reduced metabolic status or a protective cause preventing the extreme catabolism that characterizes the aging process (19). In addition, when analyzing the aging process on thyroid gland we should mention that the prevalence of specific thyroid diseases increases with age (20) and subclinical thyroid dysfunctions are more frequent than overt diseases $(7,21)$. Consistently, the prevalence of subclinical hypothyroidism and the presence of autoimmunity against thyroid cells increases with aging (20), thus underling a possible immune mechanism age related that explain this finding.

Some experiences showed that the modifications of pituitarythyroid axis during aging may have an impact on longevity (7) even if we should report that the most important results on thyroid hormones and lifespan regulation, were obtained in the studies carried out in centenarians (and almost centenarians) (20). In this regard, Atzmon et al. reported that disease-free population of Ashkenazi Jews were characterized by extreme longevity. In details, they have observed higher serum TSH level in centenarians as compared to the control group (younger unrelated Ashkenazi Jews) and also to another control group from The National Health and Nutrition Examination Survey (NHANES). Furthermore, the authors documented an inverse correlation between $\mathrm{FT}_{4}$ and TSH levels in centenarians and Ashkenazi controls. Another experience in this setting showed a possible thyroid genetic background associated to extreme longevity (22). In particular, two single nucleotide polymorphisms (SNPs) in TSH receptor (TSHR) gene (rs10149689 and rs12050077) correlated with increased TSH level in the Ashkenazi Jewish centenarians and their offspring (22). In line with this, a North Europe study (Leiden Longevity Study) confirmed the role of thyroid genetic background on lifespan regulation. Indeed, the offspring of nonagenarian population presented a low thyroid activity (reduced $\mathrm{FT}_{3}$ values) and a better metabolic profile compared to their partners with less long-lived parents (8).

Consistently, Corsonello et al. (23) demonstrated an inverse relationship between age and free thyroid hormones independently from TSH levels in a population of Southern Italy (23). Moreover, the offspring of oldest old people presented lower free triiodothyronine $\left(\mathrm{FT}_{3}\right), \mathrm{FT}_{4}$ and TSH levels when compared with age-matched controls (23). Another interesting finding related to the aging process and thyroid function were reported by Gussekloo et al. (24) who firstly showed in a cohort study that oldest old individuals with abnormally high levels of thyrotropin may have a prolonged life span (24). Interestingly, in animal models low levels of $\mathrm{T}_{4}$ were associated with extended longevity (25-29). For example, a very severe hypothyroidism leading to reduced core body temperature, substantially contributed to remarkable longevity in rodents (25).

A recent report from the Rotterdam study, including over 9,000 healthy home-dwelling subjects, does not confirm the increasing trend of TSH during age, showing instead a progressive reduction of mean serum TSH with a concomitant rising of anti-thyroid peroxidase autoantibody (TPOAb) values with increasing age (30) while the same group provided intriguing results on the peripheral $\mathrm{FT}_{4}$ values and outcome in the same cohort (31). Those with higher $\mathrm{FT}_{4}$ values at baseline presented a worse prognosis in term of frailty index (31). Consistently, other experiences in the elderly showed the importance of thyroid hormones peripheral values in term of clinical outcomes (32) reinforcing the hypothesis that, apart from TSH level in very old population, the peripheral pattern of $\mathrm{FT}_{4}$ and $\mathrm{FT}_{3}$ may also play a central role in the lifespan regulation at least in older population at risk of frailty (32).

\section{EPIDEMIOLOGY AND CLINICAL EFFECT OF OVERT AND SUBCLINICAL HYPOTHYROIDISM}

Over the last decades, the demographic growth in the Occidental Countries determined an increase of the population over 65 years of age. In Italy, which is second only to Japan in the elderly 
population, the over $80 \mathrm{~s}$ are the $6.7 \%$ of the overall population, while $22 \%$ is constituted by $>65$ (33) Together with aging, the incidence of chronic diseases increase; thyroid disturbances are frequent among the elderly. Hypothyroidism is defined by an increased level of thyroid stimulating hormone (TSH), with reduced circulating levels of free triiodothyronine $\left(\mathrm{FT}_{3}\right)$ and free thyroxine $\left(\mathrm{FT}_{4}\right)$ while, subclinical hypothyroidism ( $\mathrm{sHT}$ ) by increased TSH values in the face of normal circulating $\mathrm{FT}_{3}$ and $\mathrm{FT}_{4}$ levels $(13,20)$.

Among the general population in Europe, the prevalence of hypothyroidism varies between 0.2 and $5.3 \%$, while in the USA between 0.3 and $3.7 \%$, this variation probably being due to different iodine intake in diverse areas (34). Many factors may affect the response to excess iodine, among them route and duration of intake, iodine bioavailability and the individual physiopathological status including age, previous iodine intake and thyroid health. Indeed, excess iodine may more likely induce thyroid dysfunction (mainly hypothyroidism) in older subjects with underlying thyroid disease and insufficient iodine intake, than in those who live in iodine-sufficient areas without thyroid disease.

According to the National Health and Nutrition Survey (NHANES III), the global prevalence of hypothyroidism is $4.6 \%$, respectively $0.3 \%$ for the overt and $4.3 \%$ for the subclinical type resulting the most frequent endocrine disease in the elderly, with a greater prevalence for the female gender (11). In $\mathrm{UK}$, the prevalence of hypothyroidism is around 3.5-5\% (35). The prevalence of sHT is variable, depending on the cohort considered (20) and going from 7.5\%, as shown in the Wickham study (35) to around $21 \%$ in women and $16 \%$ in men as shown in the Colorado study (36). As demonstrated by the NANHES III study, TSH circulating levels and anti-thyroid autoantibodies increase with aging; in this study, $14 \%$ of the population 85 years old or above had TSH levels higher than $4.5 \mathrm{mUI} / \mathrm{L}$, especially in the female gender (11). In a British population of 6,000 subjects older than 65 years, the prevalence of hypothyroidism was $2 \%$, while the prevalence of sHT was around $2.9 \%$, lower than what found in literature (37). In the same geographic area, the prevalence of sHT in subjects older than 60 years was around $11.6 \%$ in females and $2.9 \%$ in males (38). The huge difference in the data for the same area after 10 years was theorized to be due to an improved screening campaign and education, together with earlier treatment (39). That explanation may be reasonable, especially considering that the Medicine Utilization Center demonstrated that $\mathrm{LT}_{4}$ is in the 10 more prescribed drugs in Italy, consistently with the worldwide projections (40).

Considering that hypothyroidism is associated with increased mortality as well as increased incidence of cardiovascular events and cognitive and functional decline, replacement therapy with $\mathrm{LT}_{4}$ is recommended (41). A population-based retrospective study evaluating more than 2,000 hypothyroid subjects older than 65 years was recently published; the results showed that such condition was independently associated with higher risk of all-causes mortality. In older population, $\mathrm{LT}_{4}$ replacement therapy was associated instead with a lower risk of mortality. The mortality rate for CVD was similar between the groups receiving or not receiving $\mathrm{LT}_{4}$ (41). The association between hypothyroidism and all-causes mortality found in that study was in line with a previous longitudinal study, in which the same association in older subjects was found (42), but inconsistent with other epidemiological studies (43-45). Thus, further large prospective, randomized controlled trials (RCT) are necessary to better evaluate the effect of hypothyroidism and $\mathrm{LT}_{4}$ replacement on cardiovascular and all-causes mortality in the elderly.

Caution needs to be taken, however, in case of subclinical hypothyroidism, in the diagnostic and therapeutic management, particularly in the oldest old (20). Large set of data are available in literature, from meta-analysis and trials, about sHT $(46,47)$ which, together with the 2013 ETA (European Thyroid Association) guideline for the management of subclinical hypothyroidism, splits the population into two groups, depending on the values of circulating TSH levels, between 4 and $10 \mathrm{mIU} / \mathrm{L}$ or above $10 \mathrm{mIU} / \mathrm{L}$ (48). Bearing in mind that the thyroid function changes with aging and TSH values tend to increase, it is important to differentiate the age-related modification from the actual gland dysfunction. The most frequent pathogenic mechanism of sHT in the elderly is Hashimoto's thyroiditis $(3,49)$, although other secondary causes, such as insufficient replacement therapy following surgical or medical procedures (i.e., thyroidectomy or radioiodine treatment) need to be always considered. Hashimoto's thyroiditis, in $90 \%$ of cases, has a positive titer of anti-thyroid antibodies [anti-thyroglobulin and/or anti-thyroid peroxidase autoantibodies ( $\mathrm{TgAb}$ and $\mathrm{TPOAb}$, respectively)]; nonetheless, thyroid tissue damage is supposed to be caused by CD8+ T-lymphocytes, rather than the auto-antibodies themselves (50). Positive anti-thyroid autoantibody titers may represent a useful information not only about the presence of autoimmune thyroiditis, but also about the chance of progression to overt hypothyroidism, which has an yearly incidence of $4.3 \%$ in $\mathrm{TPOAb}$ positive patients, compared to $2.6 \%$ in the negative ones $(50,51)$. When demonstrated, the monitoring of the titer of anti-thyroid antibodies doesn't add much information, since it varies with the TSH levels (52). In the NHANES III study, the cohort of 13,000 healthy subjects was regularly followed up; the repeated dosage of $\mathrm{FT}_{3}, \mathrm{FT}_{4}, \mathrm{TSH}, \mathrm{TgAb}$, and TPOAb, showed that $10 \%$ of the subjects were positive for $\mathrm{TgAb}$ and $11 \%$ for TPOAb (11). In the around $20 \%$ of cases of antibody-negative sHT individuals, the diagnosis would be supported by the presence of tissue inhomogeneity and hypoechogenicity at the thyroid US scan (53). Another possible cause of hypothyroidism in the elderly is iatrogenic. Drugs interfering with L-thyroxin absorption, as well as drugs potentially damaging the gland tissue such as $\beta$-blockers, interferon- $\alpha$, interleukin-2, lithium, ethionamide, tyrosin-kinase inhibitors, and thyrostatic medications (methimazole, perchlorate, and propylthiouracil), could determine hypothyroidism. The drug-induced damage is usually transient, and a periodical monitoring of the gland function, at least twice a year, is recommended (49). It has been widely accepted that thyroid hormones play a role in the cardiovascular system, modulating the adrenergic system activity, regulating the vascular peripheral resistance and in the protein synthesis (7). Unfortunately, while the impact of sHT 
on the cardiovascular (CV) system among the young adult has been recognized, among the elderly is still a matter of debate $(20,41,54)$ especially since no RCTs have been conducted so far evaluating the impact of LT4 therapy on CV outcomes. A recent study involving over 2,100 subjects longitudinally, aimed at identifying a possible relationship between sHT and metabolic syndrome in the elderly. In the population examined, TSH level above $10 \mathrm{mUI} / \mathrm{L}$ was associated with higher odds of prevalent metabolic syndrome (21); circulating TSH levels above $10 \mathrm{mUI} / \mathrm{L}$ have been demonstrated to increase the risk of heart failure (HF) as well (7). The Prospective Study of Pravastatin in the Elderly at Risk (PROSPER) showed an association between HF and sHT over a follow up period of 3.2 years, in a population of 70-82 years old subjects, for TSH circulating levels above $10 \mathrm{mUI} / \mathrm{L}$, while no association was found below that threshold (54). A large meta-analysis confirmed the association between HF and TSH levels above 10 $\mathrm{mUI} / \mathrm{L}$ (or below $0.10 \mathrm{mUI} / \mathrm{L}$ ) (46). More conflicting results has been reported for the relationship between sHT and coronary heart disease (CHD), more consistent in the younger population (7) (55), although a large meta-analysis showed an increased risk of CHD events and mortality for TSH levels above 10 $\mathrm{mUI} / \mathrm{L}$, across 35 years follow up, also adjusting for sex and age (45).

Thyroid hormones play a role in few metabolic functions, such as thermo regulation, oxygen consumption, glucose uptake, contra-insular activity, cholesterol mobilization and low-density lipoprotein (LDL) receptors expression in the liver (56). It is common, in hypothyroidism, to find increased levels of cholesterol and its sub-fractions (57); part of that is related to reduced cholesterol clearance, due to a reduced expression of the LDL receptor gene. Increased level of triglycerides is also a common finding in overt hypothyroidism, generally unmodified in sHT, following a reduced lipogenesis and lipase activities (58). The role of thyroid homeostasis in the cognitive development is widely known and accepted; not completely clear is the effect of thyroid failure, overt or mild, in the elderly and the impact it may have on cognitive impairment (59). An increased risk of Alzheimer's disease development has been seen in women at the lowest $(<1.0 \mathrm{mIU} / \mathrm{L})$ and highest $(>2.1 \mathrm{mIU} / \mathrm{L})$ tertiles of serum TSH concentration in the Framingham study (60). Other studies showed interesting results; in the Health, Aging and Body Composition study, the risk of developing dementia was higher in subclinical hyperthyroidism, but not in sHT subjects (61), results consistent with a previous meta-analysis of Rieben et al. (62). Another recent meta-analysis showed a significant relationship between higher levels of circulating TSH and impaired cognitive performance in younger population $(<75$ years of age) (63). On the other hand, a longitudinal study conducted on a cohort of cognitively normal subjects aged 6090 years didn't find any relationship between TSH and thyroid hormones and hippocampal atrophy or risk of developing dementia (64). The inconsistent results available despite the important role played by thyroid function raise the need of longterm longitudinal studies, involving elder population, including the oldest old.

\section{HYPOTHYROIDISM IN THE ELDERLY: WHEN TO TREAT?}

Consistently to the principle that the therapy of choice for glandular deficiency is the replacement therapy, for overt hypothyroidism the first choice is $\mathrm{LT}_{4}$ replacement, also in older patients (65). The appropriate treatment of hypothyroidism, dealing to the resolution of the disease, leads to the release of symptoms, such as fatigue, constipation, increased sensitivity to cold, muscle weakness, and increased weight; improvement has been demonstrated in cognitive executive and cardiovascular functions (66). When considering the treatment of sHT in the elderly (especially in those older than 75-80 years), the approach has to be more cautious. It has been demonstrated in several studies that $\mathrm{LT}_{4}$ replacement therapy should be started when the TSH values are above $10 \mathrm{mUI} / \mathrm{L}$, this being considered the value above which the risk of health disorders rises $(7,21,46,54)$. However, it is important to keep an approach on a case-by-case basis; this is particularly important in patients with potential other cardiovascular risk factors, which could hide the symptoms and signs related to sHT, already potentially less evident. Among the older population, it is also important to evaluate the potential frailty and comorbidities (66), appropriately tailoring the therapy. On that note, the evaluation of TSH levels and the trend over time is crucial; the international guidelines have set the cut-off level to $10 \mathrm{mUI} / \mathrm{L}$, double checked and confirmed over 3 and 6 months before commencing the treatment (48, 49). Other than the TSH levels, the clinician should check the clinical presentation with signs and symptoms before deciding for any therapeutic approach (48), bearing in mind that many symptoms are unspecific (i.e., fatigue, constipation, sleeping pattern alteration, and fatigue), especially in the elderly with comorbidities (32). A well-structured approach, including a multidimensional geriatric assessment (67), comprehends a wide evaluation, which includes laboratory tests $\left(\mathrm{FT}_{3}, \mathrm{FT}_{4}, \mathrm{TgAb}\right.$, TPOAb) and US scan, to identify potential causes of thyroid failure (gland atrophy or autoimmune thyroiditis), responsible for permanently increased TSH levels. Whilst TSH levels tend to increase with aging, usually they don't exceed 7-8 mIU/L (14). In addition to the laboratory and imaging evaluation, the collection of a well accurate pharmacological history for drugs potentially affecting the thyroid function, such as amiodarone, lithium etc., is very important.

In 2017, Stott et al. conducted a double blinded, randomized, placebo-controlled study aiming to evaluate the efficacy of the therapy with $\mathrm{LT}_{4}$ on a large cohort (737 subjects) of older patient (mean age 74.4 years) with persistent sHT (mean entry TSH level: $6.40 \pm 2.01 \mathrm{mIU} / \mathrm{L}$ ) (68). The primary outcomes of the study were the changes, in 1 year, in the Hypothyroid Symptoms score and Tiredness score on a thyroid-related quality-of-life questionnaire. At the follow up evaluation, at 1 year, mean serum TSH level in the treatment group was $3.63 \pm 2.11$ and $5.48 \pm 2.48 \mathrm{mIU} / \mathrm{L}$ in the placebo group. Among the groups, there were no differences in the quality of life measured with the questionnaire, nor difference in the adverse events of interest. The study concluded that the treatment with $\mathrm{LT}_{4}$ failed 
to provide an actual benefit in sHT subjects. However, some limitations in the study should be taken into account: serum TSH level at baseline was above $10 \mathrm{mUI} / \mathrm{L}$ only in few subjects, symptoms' level was low, and the presence of autoimmunity was not assessed. In particular, the latter limitation needs to be considered, since autoantibody positive patients are more likely to have progressive hypothyroidism, therefore long-term treatment could be actually beneficial (68). The study, moreover, was underpowered to detect the incidence of the $\mathrm{LT}_{4}$ therapy on cardiovascular events or mortality. Larger studies with a large cohort of older subjects with actual thyroid disease (i.e., with positive $\mathrm{Ab}$ titers) are not available at the moment. Our
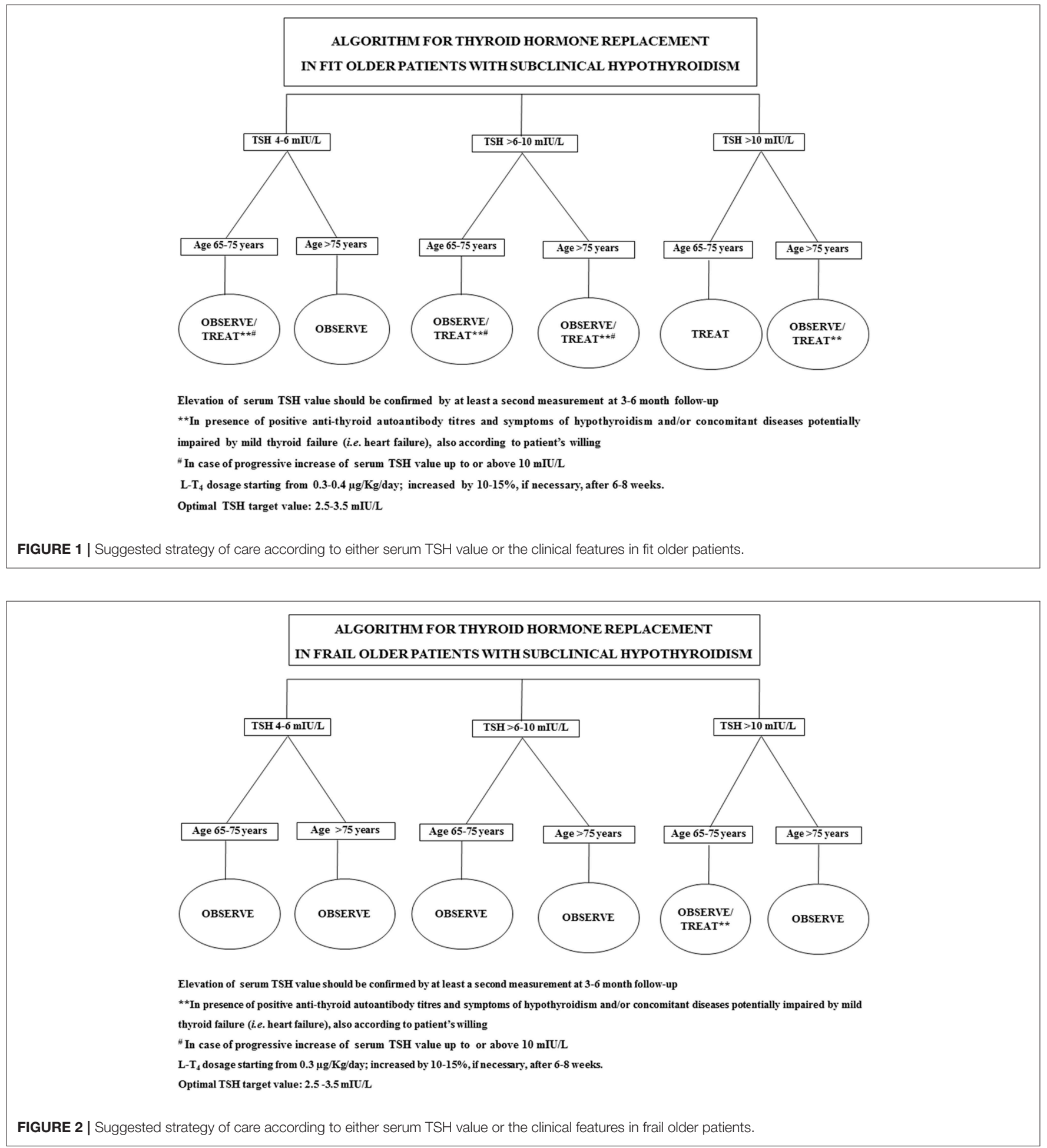
recommendation, in the elderly with sHT, is to approach the clinical management not only considering serum TSH levels and the $10 \mathrm{mUI} / \mathrm{L}$ cut-off, but also evaluating the presence of autoimmune thyroiditis as well comorbidities (especially HF) (69). On that note, the evaluation of the presence of frailty is crucial, considering how much impact it could have on the patient's quality of life and the clinical prognosis $(32,70)$ : frail subjects are more likely to be affected by drugs side effect, and the risk of overtreatment, or poor compliance needs to be accounted in the clinical workup. The suggested clinical management of sHT in either fit or frail older patients is summarized in Figures 1, 2. In case of fit older (65-75 years) patients, $\mathrm{LT}_{4}$ replacement should be commenced when TSH levels are above $10 \mathrm{mUI} / \mathrm{L}$ (48, 49 ) while, fit oldest old (>75-80 years) should be treated when clear signs and symptoms of thyroid disease are present, after careful evaluation of cardiovascular and cognitive comorbidities; in absence of that, the strategy of choice should be the observation over time, in agreement with the ETA 2013 guidelines (48). A more cautious approach is suggested in frail elderly subjects, as shown in Figure 2. In frail subjects with TSH levels above 10 $\mathrm{mUI} / \mathrm{L}$, the wait-and-see strategy should be the one of choice, treating subjects in the 65-75 years of age range in presence of actual thyroid disease, symptoms of hypothyroidism and/or comorbidities potentially worsened by mild thyroid failure (i.e., heart failure). In case of serum TSH levels between 6 and 10 $\mathrm{mUI} / \mathrm{L}, \mathrm{LT}_{4}$ replacement therapy should be considered in "fit" subjects with risks factors for thyroid disease progression, such as anti-thyroid Ab, US pattern suggestive of disease, female gender; in absence of thyroid disease progression risk factors, an observation period with follow up of thyroid function every 3-6 months is suggested, commencing the therapy if the TSH level increases above $10 \mathrm{mIU} / \mathrm{L}$ (Figure 1). In the same range of values, but in frail subjects (Figure 2), the observation strategy is the one of choice. In frail patients younger than 75 years, with TSH levels below $10 \mathrm{mIU} / \mathrm{L}$, the strategy of choice is to avoid $\mathrm{LT}_{4}$ replacement, unless the TSH level would progressively increase above $10 \mathrm{mIU} / \mathrm{L}$ during follow up, in presence of comorbidities potentially negatively influenced by mild thyroid failure, or in case of positive anti-thyroid auto antibody titers. In case of "fit" elderly younger than 75 years, with positive anti-thyroid autoantibody titer, symptoms of hypothyroidism and/or comorbidities influenced by mild thyroid failure, a trial with LT4 replacement should be considered (Figure 1). For all the subjects receiving replacement therapy, the titration of $\mathrm{LT}_{4}$ should be done from around $0.3-0.4 \mu \mathrm{g} / \mathrm{Kg} /$ day with increments by $10-15 \%$ after $6-8$ weeks, if necessary, considering the optimal target values between 2.5 and $3.5 \mathrm{mIU} / \mathrm{L}$, in agreement with international guidelines $(48,49)$. The regular monitoring and follow up of thyroid function is recommended over time, especially in the oldest old, to avoid over-treatment, which is known to negatively impact on cardiovascular an osteo-muscolar systems $(48,49)$.

Different formulations are available for the replacement therapy; the most used is the $\mathrm{LT}_{4}$ tablet, which is usually the first choice in absence of swallowing problems. However, considering the delicate process of absorption of the $\mathrm{LT}_{4}$, which can be influenced by several gastro-intestinal factors (71), some "rules" in regards of food and concomitant drugs administration should be followed $(48,49)$.

A debate is still open regarding the use of combined therapy $\mathrm{T}_{4}+\mathrm{T}_{3}$. Few studies have been conducted; most of the studies evaluated in a recent review of the literature failed to demonstrate a clear advantage with the combined therapy (72). The same lack of advantage over the monotherapy has been seen also in two different meta-analyses $(73,74)$. A large study evaluating the outcomes over 17 years follow up in population undertaking $\mathrm{T}_{3}$, mostly associated with $\mathrm{T}_{4}$, compared to a population receiving only $\mathrm{LT}_{4}$, didn't show any difference in the cardiovascular events, atrial fibrillation, fractures, diabetes mellitus or death; the group receiving $\mathrm{T}_{3}$ showed an increased rate of use of antipsychotic drugs (75). According to the 2012 ETA guidelines (10), the combined therapy $\mathrm{T}_{4} / \mathrm{T}_{3}$ should be used only in case of persistent complaint from the patient despite normal values of TSH with the monotherapy, after adequate education regarding the chronicity of the thyroid condition. Moreover, the combined therapy should be interrupted if the clinical improvement is not reached within 3 months (76). Thus, taking in mind the potential drawbacks of $\mathrm{T}_{3}$ therapy, the combined treatment with $\mathrm{T}_{4} / \mathrm{T}_{3}$ is generally not advised in older hypothyroid patients, especially in those older than 75 years.

Considering how variable the thyroid hormones could be among the general population, due to the influence of genetic, demographic (i.e., age and gender) and environmental factors, it is important to tailor and personalize the individual's treatment and follow up approach.

\section{CONCLUSIONS}

Hypothyroidism, overt or subclinical, is a very frequent chronic disease among the older population; however, TSH circulating levels have been demonstrated to increase with aging, regardless the existence of an actual thyroid disease. For this reason, when confronting an increase in TSH circulating level in a patient older than 65 years of age, and even more carefully in the oldest old, it is important to carry an appropriate diagnostic path, comprehensive of clinical picture, laboratory tests, in particular checking for anti-thyroid autoantibodies, and US scan. Moreover, in the older population, the presence of frailty needs to be considered and addressed (77). The therapy of choice is hormone replacement with $\mathrm{LT}_{4}$, whichever pharmacologic form is more adequate, starting with a dosage of $0.3-0.4 \mu \mathrm{g} / \mathrm{Kg} /$ day and titrating by $10-15 \%$ after $6-8$ weeks, aiming to keep an optimal TSH level of $2.5-3.5 \mathrm{mIU} / \mathrm{L}$. It is important to stress the need of educating the patient for a correct administration of the therapy, particularly when poly-therapy is in place and the importance of a tailored therapeutic approach and follow up, to avoid overtreatment.

\section{AUTHOR CONTRIBUTIONS}

All authors listed have made a substantial, direct and intellectual contribution to the work, and approved it for publication. 


\section{REFERENCES}

1. Dietrich JW, Midgley JEM, Hoermann R. Editorial: "homeostasis and allostasis of thyroid function". Front Endocrinol. (2018) 9:287. doi: 10.3389/fendo.2018.00287

2. Andersen S, Pedersen KM, Bruun NH, Laurberg P. Narrow individual variations in serum $\mathrm{T}(4)$ and $\mathrm{T}(3)$ in normal subjects: a clue to the understanding of subclinical thyroid disease. J Clin Endocrinol Metab. (2002) 87:1068-72. doi: 10.1210/jcem.87.3.8165

3. Braverman L, Utiger R. Werner and Ingbar's. The Thyroid, a Fundamental and Clinical Text. Philadelphia, PA: Lippincott Williams \& Wilkins (2005). p. 697.

4. Mariotti S, Franceschi C, Cossarizza A, Pinchera A. The aging thyroid. Endocr Rev. (1995) 16:686-715.

5. Monzani F, Del Guerra P, Caraccio N, Del Corso L, Casolaro A, Mariotti $\mathrm{S}$, et al. Age-related modifications in the regulation of the hypothalamicpituitary-thyroid axis. Horm Res. (1996) 46:107-12.

6. van den Beld AW, Visser TJ, Feelders RA, Grobbee DE, Lamberts SWJ. Thyroid hormone concentrations, disease, physical function, and mortality in elderly men. J Clin Endocr Metab. (2005) 90:6403-9. doi: 10.1210/jc.2005-0872

7. Pasqualetti G, Tognini S, Polini A, Caraccio N, Monzani F. Is subclinical hypothyroidism a cardiovascular risk factor in the elderly? J Clin Endocr Metab. (2013) 98:2256-66. doi: 10.1210/jc.2012-3818

8. Rozing MP, Houwing-Duistermaat JJ, Slagboom PE, Beekman M, Frolich M, de Craen AJM, et al. Familial longevity is associated with decreased thyroid function. J Clin Endocr Metab. (2010) 95:4979-84. doi: 10.1210/ jc.2010-0875

9. Tognini S, Polini A, Pasqualetti G, Ursino S, Caraccio N, Ferdeghini M, et al. Age and gender substantially influence the relationship between thyroid status and the lipoprotein profile: results from a large cross-sectional study. Thyroid. (2012) 22:1096-103. doi: 10.1089/thy.2012.0013

10. Braverman LE, Cooper D. Nonthyroidal illness syndrome. In: Braverman LE, Cooper D, editors. Werner \& Ingbar's the thyroid, a Fundamental and Clinical Text, 9th ed (2004). p. 246-63.

11. Hollowell JG, Staehling NW, Flanders WD, Hannon WH, Gunter EW, Spencer CA, et al. Serum TSH, T(4), and thyroid antibodies in the United States population (1988 to 1994): National Health and Nutrition Examination Survey (NHANES III). J Clin Endocrinol Metab. (2002) 87:48999. doi: 10.1210/jcem.87.2.8182

12. Schlageter NL, Carson RE, Rapoport SI. Examination of blood-brain barrier permeability in dementia of the Alzheimer type with [68Ga]EDTA and positron emission tomography. J Cereb Blood Flow Metab. (1987) 7:1-8.

13. Biondi B, Cooper DS. The clinical significance of subclinical thyroid dysfunction. Endocr Rev. (2008) 29:76-131. doi: 10.1210/er.2006-0043

14. Hennessey JV, Espaillat R. Subclinical hypothyroidism: a historical view and shifting prevalence. Int J Clin Pract. (2015) 69:771-82. doi: 10.1111/ijcp.12619

15. Sawin CT, Chopra D, Azizi F, Mannix JE, Bacharach P. Aging thyroid increased prevalence of elevated serum thyrotropin levels in the elderly. J Am Med Assoc. (1979) 242:247-50.

16. Surks MI, Hollowell JG. Age-specific distribution of serum thyrotropin and antithyroid antibodies in the US population: implications for the prevalence of subclinical hypothyroidism. J Clin Endocrinol Metab. (2007) 92:4575-82. doi: 10.1210/jc.2007-1499

17. Mariotti S, Barbesino G, Caturegli P, Bartalena L, Sansoni P, Fagnoni F, et al. Complex alteration of thyroid-function in healthy centenarians. J Clin Endocr Metab. (1993) 77:1130-4.

18. Tognini S, Marchini F, Dardano A, Polini A, Ferdeghini M, Castiglioni M, et al. Non-thyroidal illness syndrome and short-term survival in a hospitalised older population. Age Ageing. (2010) 39:46-50. doi: 10.1093/ageing/afp197

19. Piers LS, Soares MJ, McCormack LM, O'Dea K. Is there evidence for an age-related reduction in metabolic rate? J Appl Physiol. (1998) 85:2196-204.

20. Cooper DS, Biondi B. Subclinical thyroid disease. Lancet. (2012) 379:1142-54. doi: 10.1016/S0140-6736(11)60276-6

21. Waring AC, Rodondi N, Harrison S, Kanaya AM, Simonsick EM, Miljkovic I, et al. Thyroid function and prevalent and incident metabolic syndrome in older adults: the Health, Ageing and Body Composition Study. Clin Endocrinol. (2012) 76:911-8. doi: 10.1111/j.1365-2265.2011. 04328.x
22. Atzmon G, Barzilai N, Surks MI, Gabriely I. Genetic predisposition to elevated serum thyrotropin is associated with exceptional longevity. J Clin Endocr Metab. (2009) 94:4768-75. doi: 10.1210/jc.2009-0808

23. Corsonello A, Montesanto A, Berardelli M, De Rango F, Dato S, Mari V, et al. A cross-section analysis of FT3 age-related changes in a group of old and oldestold subjects, including centenarians' relatives, shows that a down-regulated thyroid function has a familial component and is related to longevity. Age Ageing. (2010) 39:723-7.

24. Gussekloo J, van Exel E, de Craen AJ, Meinders AE, Frolich M, Westendorp RG. Thyroid status, disability and cognitive function, and survival in old age. JAMA. (2004) 292:2591-9. doi: 10.1001/jama.292.21.2591

25. Brown-Borg HM. Hormonal regulation of longevity in mammals. Ageing Res Rev. (2007) 6:28-45. doi: 10.1016/j.arr.2007.02.005

26. Buffenstein R, Pinto $M$. Endocrine function in naturally longliving small mammals. Mol Cell Endocrinol. (2009) 299:101-11. doi: 10.1016/j.mce.2008.04.021

27. Edrey YH, Park TJ, Kang H, Biney A, Buffenstein R. Endocrine function and neurobiology of the longest-living rodent, the naked mole-rat. Exp Gerontol. (2011) 46:116-23. doi: 10.1016/j.exger.2010.09.005

28. Gesing A, Bartke A, Masternak MM, Lewinski A, Karbownik-Lewinska M. Decreased thyroid follicle size in dwarf mice may suggest the role of growth hormone signaling in thyroid growth regulation. Thyroid Res. (2012) 5:7. doi: 10.1186/1756-6614-5-7

29. Gesing A, Lewinski A, Karbownik-Lewinska M. The thyroid gland and the process of aging; what is new? Thyroid Res. (2012) 5:16. doi: 10.1186/1756-6614-5-16

30. Chaker L, Korevaar TI, Medici M, Uitterlinden AG, Hofman A, Dehghan A, et al. Thyroid function characteristics and determinants: the Rotterdam Study. Thyroid. (2016) 26:1195-204. doi: 10.1089/thy.2016.0133

31. Bano A, Chaker L, Schoufour J, Ikram MA, Kavousi M, Franco OH, et al. High circulating free thyroxine levels may increase the risk of frailty: the Rotterdam Study. J Clin Endocr Metab. (2018) 103:328-35. doi: 10.1210/jc.2017-01854

32. Pasqualetti G, Calsolaro V, Bernardini S, Linsalata G, Bigazzi R, Caraccio $\mathrm{N}$, et al. Degree of peripheral thyroxin deiodination, frailty, and longterm survival in hospitalized older patients. J Clin Endocrinol Metab. (2018) 103:1867-76. doi: 10.1210/jc.2017-02149

33. Eurostat EUROPOP13 Database, Main Scenario. Available online at: ec. europa.eu/eurostat/web/population-demography-migration-projections/ population-projections-data

34. Taylor PN, Albrecht D, Scholz A, Gutierrez-Buey G, Lazarus JH, Dayan CM, et al. Global epidemiology of hyperthyroidism and hypothyroidism. Nat Rev Endocrinol. (2018) 14:301-16. doi: 10.1038/nrendo.2018.18

35. Vanderpump MP, Tunbridge WM, French JM, Appleton D, Bates D, Clark $\mathrm{F}$, et al. The incidence of thyroid disorders in the community: a twenty-year follow-up of the Whickham Survey. Clin Endocrinol. (1995) 43:55-68.

36. Canaris GJ, Manowitz NR, Mayor G, Ridgway EC. The Colorado thyroid disease prevalence study. Arch Intern Med. (2000) 160:52634. doi:10.1001/archinte.160.4.526

37. Wilson S, Parle JV, Roberts LM, Roalfe AK, Hobbs FD, Clark P, et al. Prevalence of subclinical thyroid dysfunction and its relation to socioeconomic deprivation in the elderly: a community-based cross-sectional survey. J Clin Endocrinol Metab. (2006) 91:4809-16. doi: 10.1210/jc.2006-1557

38. Parle JV, Franklyn JA, Cross KW, Jones SC, Sheppard MC. Prevalence and follow-up of abnormal thyrotrophin (TSH) concentrations in the elderly in the United Kingdom. Clin Endocrinol. (1991) 34:77-83.

39. Franklyn JA. The thyroid-too much and too little across the ages. The consequences of subclinical thyroid dysfunction. Clin Endocrinol. (2013) 78:1-8. doi: 10.1111/cen.12011

40. Agency IM. The Medicines Utilization Monitoring Centre. National Report on Medicines use in Italy 2016 (2017).

41. Huang HK, Wang JH, Kao SL. Association of hypothyroidism with All-cause mortality: a Cohort Study in an older adult population. J Clin Endocrinol Metab. (2018) 103:3310-8. doi: 10.1210/jc.2018-00408

42. Grossman A, Weiss A, Koren-Morag N, Shimon I, Beloosesky Y, Meyerovitch J. Subclinical thyroid disease and mortality in the elderly: a Retrospective Cohort Study. Am J Med. (2016) 129:423-30. doi: 10.1016/j.amjmed.2015.11.027 
43. Ceresini G, Ceda GP, Lauretani F, Maggio M, Usberti E, Marina M, et al. Thyroid status and 6-year mortality in elderly people living in a mildly iodinedeficient area: the aging in the Chianti Area Study. J Am Geriatr Soc. (2013) 61:868-74. doi: 10.1111/jgs.12267

44. Pearce SH, Razvi S, Yadegarfar ME, Martin-Ruiz C, Kingston A, Collerton J, et al. Serum thyroid function, mortality and disability in advanced old age: the Newcastle 85+ Study. J Clin Endocrinol Metab. (2016) 101:4385-94. doi: 10.1210/jc.2016-1935

45. Waring AC, Harrison S, Samuels MH, Ensrud KE, Le BES, Hoffman AR, et al. Thyroid function and mortality in older men: a prospective study. J Clin Endocrinol Metab. (2012) 97:862-70. doi: 10.1210/jc.2011-2684

46. Gencer B, Collet TH, Virgini V, Bauer DC, Gussekloo J, Cappola AR, et al. Subclinical thyroid dysfunction and the risk of heart failure events an individual participant data analysis from 6 prospective cohorts. Circulation. (2012) 126:1040-U100. doi: 10.1161/CIRCULATIONAHA.112.096024

47. Rodondi N, den Elzen WP, Bauer DC, Cappola AR, Razvi S, Walsh JP, et al. Subclinical hypothyroidism and the risk of coronary heart disease and mortality. JAMA. (2010) 304:1365-74. doi: 10.1001/jama.2010.1786

48. Pearce SH, Brabant G, Duntas LH, Monzani F, Peeters RP, Razvi S, et al. 2013 ETA guideline: management of subclinical hypothyroidism. Eur Thyroid J. (2013) 2:215-28. doi: 10.1159/000356507

49. Jonklaas J, Bianco AC, Bauer AJ, Burman KD, Cappola AR, Celi FS, et al. Guidelines for the treatment of hypothyroidism: prepared by the american thyroid association task force on thyroid hormone replacement. Thyroid. (2014) 24:1670-751. doi: 10.1089/thy.2014.0028

50. Mariotti S, Caturegli P, Piccolo P, Barbesino G, Pinchera A. Antithyroid peroxidase autoantibodies in thyroid diseases. J Clin Endocrinol Metab. (1990) 71:661-9. doi: 10.1210/jcem-71-3-661

51. Huber G, Staub JJ, Meier C, Mitrache C, Guglielmetti M, Huber P, et al. Prospective study of the spontaneous course of subclinical hypothyroidism: prognostic value of thyrotropin, thyroid reserve, and thyroid antibodies. JClin Endocrinol Metab. (2002) 87:3221-6. doi: 10.1210/jcem.87.7.8678

52. Karmisholt J, Andersen S, Laurberg P. Variation in thyroid function in subclinical hypothyroidism: importance of clinical follow-up and therapy. Eur J Endocrinol. (2011) 164:317-23. doi: 10.1530/EJE-10-1021

53. Pedersen OM, Aardal NP, Larssen TB, Varhaug JE, Myking O, Vik-Mo H. The value of ultrasonography in predicting autoimmune thyroid disease. Thyroid. (2000) 10:251-9. doi: 10.1089/thy.2000.10.251

54. Nanchen D, Gussekloo J, Westendorp RGJ, Stott DJ, Jukema JW, Trompet S, et al. Subclinical thyroid dysfunction and the risk of heart failure in older persons at high cardiovascular risk. J Clin Endocr Metab. (2012) 97:852-61. doi: 10.1210/jc.2011-1978

55. Sun J, Yao L, Fang Y, Yang RF, Chen YL, Yang KH, et al. Relationship between subclinical thyroid dysfunction and the risk of cardiovascular outcomes: a systematic review and meta-analysis of prospective cohort studies. Int J Endocrinol. (2017) 2017:8130796. doi: 10.1155/2017/8130796

56. Duntas LH. Thyroid disease and lipids. Thyroid. (2002) 12:287-93. doi: 10.1089/10507250252949405

57. Pearce EN. Hypothyroidism and dyslipidemia: modern concepts and approaches. Curr Cardiol Rep. (2004) 6:451-6. doi: 10.1007/s11886-004-0054-3

58. Solini A, Monzani F. Hypothyroidism and intermediate metabolism: a complex relationship. Thyroid. (2010) 20:837-9. doi: 10.1089/thy.2010.1652

59. Szlejf C, Suemoto CK, Santos IS, Lotufo PA, Haueisen Sander Diniz MF, Barreto SM, et al. Thyrotropin level and cognitive performance: baseline results from the ELSA-Brasil Study. Psychoneuroendocrinology. (2018) 87:1528. doi: 10.1016/j.psyneuen.2017.10.017

60. Tan ZS, Beiser A, Vasan RS, Au R, Auerbach S, Kiel DP, et al. Thyroid function and the risk of Alzheimer disease: the Framingham Study. Arch Intern Med. (2008) 168:1514-20. doi: 10.1001/archinte.168.14.1514

61. Aubert CE, Bauer DC, da Costa BR, Feller M, Rieben C, Simonsick EM, et al. The association between subclinical thyroid dysfunction and dementia: the Health, Aging and Body Composition (Health ABC) Study. Clin Endocrinol. (2017) 87:617-26. doi: 10.1111/cen.13458

62. Rieben C, Segna D, da Costa BR, Collet TH, Chaker L, Aubert CE, et al. Subclinical thyroid dysfunction and the risk of cognitive decline: a meta- analysis of prospective cohort studies. J Clin Endocr Metab. (2016) 101:494554. doi: 10.1210/jc.2016-2129

63. Pasqualetti G, Pagano G, Rengo G, Ferrara N, Monzani F. Subclinical Hypothyroidism and Cognitive Impairment: systematic review and metaanalysis. J Clin Endocr Metab. (2015) 100:4240-8. doi: 10.1210/jc.2015-2046

64. de Jong FJ, den Heijer T, Visser TJ, de Rijke YB, Drexhage HA, Hofman A, et al. Thyroid hormones, dementia, and atrophy of the medial temporal lobe. J Clin Endocrinol Metab. (2006) 91:2569-73. doi: 10.1210/jc.2006-0449

65. Garber JR, Cobin RH, Gharib H, Hennessey JV, Klein I, Mechanick JI, et al. Clinical practice guidelines for hypothyroidism in adults: cosponsored by the American Association of Clinical Endocrinologists and the American Thyroid Association. Endocr Pract. (2012) 18:988-1028. doi: 10.4158/EP12280.GL

66. Ruggeri RM, Trimarchi F, Biondi B. MANAGEMENT OF ENDOCRINE DISEASE: 1-thyroxine replacement therapy in the frail elderly: a challenge in clinical practice. Eur J Endocrinol. (2017) 177:R199-217. doi: 10.1530/EJE-17-0321

67. Parker SG, Mccue P, Phelps K, McCleod A, Arora S, Nockels K, et al. What is Comprehensive Geriatric Assessment (CGA)? An umbrella review. Age Ageing. (2018) 47:149-55. doi: 10.1093/ageing/afx166

68. Stott DJ, Rodondi N, Bauer DC, Group TS. Thyroid hormone therapy for older adults with subclinical hypothyroidism. N Engl J Med. (2017) 377:e20. doi: 10.1056/NEJMoa1603825

69. Pasqualetti G, Tognini S, Polini A, Caraccio N, Monzani F. Subclinical hypothyroidism and heart failure risk in older people. Endocr Metab Immune Disord Drug Targets. (2013) 13:13-21. doi: 10.2174/1871530311313010004

70. Fried LP, Tangen CM, Walston J, Newman AB, Hirsch C, Gottdiener J, et al. Frailty in older adults: evidence for a phenotype. J Gerontol A Biol Sci Med Sci. (2001) 56:M146-56. doi: 10.1093/gerona/56.3.M146

71. Virili C, Giovanella L, Fallahi P, Antonelli A, Santaguida MG, Centanni M, et al. Levothyroxine therapy: changes of TSH levels by switching patients from tablet to liquid formulation. a systematic review and meta-analysis. Front Endocrinol. (2018) 9:10. doi: 10.3389/fendo.2018.00010

72. Hennessey JV, Espaillat R. Current evidence for the treatment of hypothyroidism with levothyroxine/levotriiodothyronine combination therapy versus levothyroxine monotherapy. Int J Clin Pract. (2018) 72:e13062. doi: 10.1111/ijcp.13062

73. Grozinsky-Glasberg S, Fraser A, Nahshoni E, Weizman A, Leibovici L. Thyroxine-triiodothyronine combination therapy versus thyroxine monotherapy for clinical hypothyroidism: meta-analysis of randomized controlled trials. J Clin Endocrinol Metab. (2006) 91:2592-9. doi: $10.1210 /$ jc.2006-0448

74. Ma C, Xie J, Huang X, Wang G, Wang Y, Wang X, et al. Thyroxine alone or thyroxine plus triiodothyronine replacement therapy for hypothyroidism. Nucl Med Commun. (2009) 30:586-93. doi: 10.1097/MNM.0b013e328 $32 \mathrm{c} 79 \mathrm{e} 0$

75. Leese GP, Soto-Pedre E, Donnelly LA. Liothyronine use in a 17 year observational population-based study - the tears study. Clin Endocrinol. (2016) 85:918-25. doi: 10.1111/cen.13052

76. Wiersinga WM, Duntas L, Fadeyev V, Nygaard B, Vanderpump MP. 2012 ETA guidelines: the use of L-T4 + L-T3 in the treatment of hypothyroidism. Eur Thyroid J. (2012) 1:55-71. doi: 10.1159/000339444

77. Calsolaro V, Niccolai F, Pasqualetti G, Tognini S, Magno S, Riccioni T, et al. Hypothyroidism in the elderly: who should be treated and how? J Endocr Soc. (2018) 3:146-58. doi: 10.1210/js.2018-00207

Conflict of Interest Statement: The authors declare that the research was conducted in the absence of any commercial or financial relationships that could be construed as a potential conflict of interest.

Copyright (C) 2019 Calsolaro, Niccolai, Pasqualetti, Calabrese, Polini, Okoye, Magno, Caraccio and Monzani. This is an open-access article distributed under the terms of the Creative Commons Attribution License (CC BY). The use, distribution or reproduction in other forums is permitted, provided the original author(s) and the copyright owner(s) are credited and that the original publication in this journal is cited, in accordance with accepted academic practice. No use, distribution or reproduction is permitted which does not comply with these terms. 